\title{
REPAIR POTENTIALITY OF CAD/CAM COMPOSITE BLOCK AND HYBRID CERAMIC BLOCK BY DIRECT RESIN COMPOSITE RESTORATION WITH AND WITHOUT SURFACE TREATMENT
}

\author{
Ahmed El Zohairy*, Amir Hafez** and Haitham Amr ${ }^{* * *}$
}

\begin{abstract}
Objective: to evaluate microshear bond strength of CAD/CAM composite block and hybrid ceramic block repaired by direct resin composite restoration with and without surface treatment.

Materials and Methods: Two different CAD/CAM restorative materials were tested in the present study: hybrid ceramic blocks (Vita Enamic) and resin composite blocks (Grandio). Six sections were prepared from each CAD/CAM blocks. The sections from each block type were randomly divided into three groups according to the surface treatment performed. Control group: the specimens were ground with a grinding machine. Etching gel Group: 37\% phosphoric acid etching gel was applied occlusally on the surface of the section and CoJet Group. the surface of all groups were then silanized using Bis-Silane then bonding agent Futura bond DC was applied. A polyethylene micro tubes were prepared that were held in place with a tweezer on the uncured then light cured for 10 seconds Resin composite (Grandioso X-tra) was packed inside the microtubes and light cured. All specimens were prepared by the same operator at $22.0-22.5^{\circ} \mathrm{C}$ (room temperature) and relative humidity of $50 \%$. The specimens were further divided into two groups according to storage conditions. Half of the specimens were thermocycled in distilled water for 5000 cycles in a $5-55^{\circ} \mathrm{C}$ water bath with a dwell time of 30 seconds and a transfer time of 5 seconds. The other specimens were stored in distilled water for 2 days. Microshear bond strength was performed and fractographic analysis to determine the failure mode. Statistical analysis was then performed using a commercially available software program (SPSS 19; SPSS, Chicago, IL, USA). As data were not normally distributed, significance of the difference between different groups within the same surface pretreatment was evaluated using Kruskall Wallis test. Mann Whitney U test was used for pairwise comparisons and to study the effect of surface pre-treatment. The interaction of restoration and type of pretreatment variables was evaluated using 3 ways ANOVA. The level of significance was set at $\mathrm{P}<0.05$.
\end{abstract}

\footnotetext{
* Ass. Professor of Conservative Dentistry, Faculty of Dentistry, Cairo University

** Lecturer of Conservative Dentistry, Faculty of Dentistry, Cairo University

** Lecturer of Fixed Prosthodontic, Faculty of Dentistry, Fayoum University
} 
Results: Three ways ANOVA test revealed that each of the material type (composite/hybrid ceramic), the subgroup type group (control/etching/Cojet) and the thermocycling (Yes/No) variables resulted in a statistically significant difference $(\mathrm{p}=0.00, \mathrm{p}=0.00, \mathrm{p}=0.003$ respectively). Interaction of the subgroup (control/etching/Cojet) variable with the thermocycling (Yes/No) variable and the material (composite/hybrid ceramic) variable showed a statistically significant difference $(\mathrm{P}=0.023, \mathrm{p}=0.001$ respectively). Moreover, interaction of thermocycling and material variable resulted in a significant difference $(\mathrm{p}=0.034)$. However, interaction of the 3 study variables (material, subgroup, thermocycling) was not statistically significant $(\mathrm{p}=0.165)$. The failure mode of the tested specimens analyzed using Scanning Electron Microscope at magnification 80X was commonly mixed type of failure (adhesive failure between resin composite restoration and CAD/ CAM blocks with cohesive failure within resin composite restoration).

Conclusions: Grandio composite blocks is very promising materials and their optimum long lasting repair potentiality that offers to the clinicians great chance to easily repair the defective restoration with safety. Surface treatment using Phosphoric acid or Cojet system greatly improve the bond strength between composite repair system and hybrid ceramic or composite blocks. The bond performance of repaired composite blocks was much more greater than than that repaired hybrid ceramic. Thermocycling affect the bond durability of repaired hybrid ceramic blocks and composite blocks.Further investigations focusing on the effect of different surface treatments to yield results that lead to concrete clinical recommendations are needed to evaluate the long term durability of new CAD/CAM materials.

\section{INTRODUCTION}

The evolution of CAD/CAM technology is one of the most active fields in esthetic dentistry. This technology has led to the research and development of different materials appropriate for CAD/CAM applications that is considered a revolution used for many dental applications ${ }^{(1,2)}$. There are different categories of materials available to the dentist (chairside): ceramic blocks, ceramic/glass-polymer blocks (hybrid ceramic) and resin-composite blocks (3). Ceramics blocks have excellent esthetic, optical and mechanical properties, chemical stability and biocompatibility as well. However, they tend to be rigid and brittle ${ }^{(1-3)}$. A polymer-infiltrated-ceramicnetwork material (hybrid ceramic) showing similar properties to the tooth structure, could be classified as interpenetrating phase composites. This structure combines the positive properties of ceramics and composites. Moreover, the material has low rigidity, brittleness and hardness, high flexibility, and fracture toughness ${ }^{(4)}$. CAD/CAM processed composite resin blocks were introduced. The main advantage of $\mathrm{CAD} / \mathrm{CAM}$ resin composite blocks over the conventional resin composite material is that the curing part is not required for $\mathrm{CAD} / \mathrm{CAM}$ resin composite blocks as they are pre-polymerized into ready-to-mill blocks. This controlled and optimized curing may lead to a superiority of resin composite blocks over conventional resin composite material due to more homogeneity, no operator related variables, and mechanical characteristics ${ }^{(3-7)}$.

Studies evaluating mechanical properties have reported indecisive results when comparing $\mathrm{CAD} /$ CAM ceramic materials to Resin composite blocks. Resin composite blocks are predictable to have more fracture resistant compared to glass ceramics, especially in restorations with limited thickness ${ }^{(6)}$, and the fatigue resistant and flexure strength have been described to be better or comparable to that of ceramic as well ${ }^{(7-9)}$.

Both glass-ceramics/ceramic blocks and resin-composite blocks are placed into a tough and unsympathetic oral environment where they are exposed to relatively high mechanical loads (cyclical loading), in addition to a major changes in both thermal and $\mathrm{pH}$-cycling values, together with changes in the salivary flow rate and buffering capacity over time. All these factors represent great 
challenges on the chemical and physical properties of the materials to accomplish the expected clinical performance and longevity ${ }^{(8-12)}$.

Fracture of dental ceramics or resin composite blocks is still the major problem in restorative dentistry. The tough oral environmental factors together with the presence of any micro-defects in the material or imperfect design are the main reasons for their fracture ${ }^{(13-16)}$. Intra oral ceramic repair might be an economic and time saving solution than repeating the whole ceramic restoration. It could be performed by five steps of treatment: (1) polishing and roughening, (2) Grit blasting, (3) acid etching, (4) Silanization, and (5) restoration with direct composite restoration ${ }^{(13-16)}$.

Bonding between resin composite materials to indirect dental restorations is a vital factor for clinical success. Silane coupling agents are indicated in cementation of indirect ceramic restorations, ceramic laminates, and ceramic repairs, E-glass fiber reinforced resin composites, and filler reinforced resin composites. Surface treatment of indirect dental restorative materials (ceramics, and resin composite), followed by silica coating and silanization, is a critical step that has been reported to their ability to activate the substrate surface for durable adhesion with resin composites. The CoJet ${ }^{\circledR}$ system is a chair-side version of the Rocatec $\AA$ System, and used for intra-oral repairs with resin composite using $30 \mu \mathrm{m}$ silica coated alumina powder ${ }^{(17-20)}$. For ceramic restorations, a micro-porous and microretentive surface is produced after etching with 9-10\% hydrofluoric acid, HF, gel. However, $\mathrm{HF}$ is hazardous and very corrosive. An alternative 35-37\% phosphoric acid gel has been tried to be used but the bond strength was lower compared to etching with $\mathrm{HF}^{(20)}$.

Therefore, the aim of this study was to evaluate microshear bond strength of CAD/CAM composite block and hybrid ceramic block repaired by direct resin composite restoration with and without surface treatment.

\section{MATERIALS AND METHODS}

\section{Specimens preparation}

Two different CAD/CAM restorative materials were tested in the present study: hybrid ceramic blocks (Vita Enamic) and resin composite blocks (Grandio). All the materials used in this study, their compositions and Manufacturers are presented in Table 1.Six sections were prepared from each CAD/ CAM blocks using a slow-speed diamond wafering blade (Ernst Leitz GmbH, Wetzlar, Germany) with a thickness of $1.5 \mathrm{~mm}$. The specimens were and embedded in an acrylic resin mold. The sections from each block type were randomly divided into three groups according to the surface treatment performed. Control group: the specimens were ground occlusally with silicone carbide abrasive up to paper no. 1000 under water cooling with a grinding machine (Struers RotoPol 11; Struers A/S, Rodovre, Denmark). Etching gel Group: $37 \%$ phosphoric acid etching gel (Pentron Clinical) was applied occlusally on the surface of the section for 60 seconds and rinsed with deionized water for 2 min. CoJet Group: the surface of the prepared sections were treated with The CoJet ${ }^{\circledR}$ system using $30 \mu \mathrm{m}$ silica coated alumina powder. the surface of all groups were then silanized according to manufacturer instructions using Bis-Silane (Bisco) for 60 seconds and air dried for 5 seconds then bonding agent Futura bond DC was applied according to the manufacturer instruction using microbrush. A polyethylene micro tubes with $0.9 \mathrm{~mm}$ internal diameter and $1 \mathrm{~mm}$ length were prepared $(n=7)$ so that each section will receive 7 microtubes that were held in place with a tweezer on the uncured adhesive before packing of the resin composite into them, then light cured for 10 seconds using LED light curing unit using BlueLex LED LD105curing unit (Monitex, Taiwan) (light intensity 1000mw/cm2). Resin composite (Grandioso X-tra) was packed inside the microtubes and light cured for 20 seconds. Excess resin composite and the 
microtubes were carefully removed using sharp scalpel. All specimens were prepared by the same operator at $22.0-22.5{ }^{\circ} \mathrm{C}$ (room temperature) and relative humidity of $50 \%$. The specimens were further divided into two groups according to storage conditions. Half of the specimens were thermocycled in distilled water for 5000 cycles in a $5-55^{\circ} \mathrm{C}$ water bath with a dwell time of 30 seconds and a transfer time of 5 seconds. The other specimens were stored in distilled water for 2 days.

\section{Microshear bond strength test}

The specimens were secured in a mounting jig and loaded with a load cell of 5KN with a sheartip of circular shape using universal testing machine (Lloyd, Fareham, Hants, UK). Bond strength was determined in micro-shear mode at a crosshead speed of $0.5 \mathrm{~mm} / \mathrm{min}$ until fracture occurred. Microshear bond strength was calculated by dividing the maximum load at failure $(\mathrm{N})$ with the bonding area $\left(\mathrm{mm}^{2}\right)$ and recorded in mega pascals $(\mathrm{MPa})$ and data were recorded using computer software (NexygenMT LLyod Instruments).

\section{Fractographic analysis}

One specimen was randomly selected from each group and prepared for SEM analysis using environmental scanning electron microscope (ESEM). Failure modes were analyzed using Scanning Electron Microscope SEM Model Quanta 250 FEG (Field Emission Gun) (FEI company, Netherlands) attached with EDX Unit (Energy Dispersive X-ray Analyses), with accelerating voltage $30 \mathrm{~K}$.V., at magnification 80X and classified as follows: adhesive failure between resin composite restoration and $\mathrm{CAD} / \mathrm{CAM}$ blocks, cohesive failure within CAD/CAM blocks or resin composite restoration and mixed type of failure.

TABLE (1) Materials used in the study

\begin{tabular}{|c|c|c|c|c|}
\hline Material & Type & Manufacturer & Lot no. & Composition \\
\hline Vita Enamic & $\begin{array}{l}\text { Polymer infiltrated } \\
\text { CAD-CAM block }\end{array}$ & $\begin{array}{l}\text { Vita } \quad \text { Zahnfabrik, } \\
\text { Bad } \quad \text { Säckingen, } \\
\text { Germany }\end{array}$ & & $86 \mathrm{wt} \%$ feldspar ceramic, $14 \mathrm{wt} \%$ polymer \\
\hline Grandio & $\begin{array}{l}\text { Nano- Hybrid composite } \\
\text { CAD / CAM block }\end{array}$ & $\begin{array}{l}\text { Voco } \\
\text { Germany, Cuxhaven }\end{array}$ & & $86 \% \mathrm{w} / \mathrm{w}$ inorganic fillers in a polymer matrix. \\
\hline Grandioso X-tra & $\begin{array}{l}\text { nano-hybrid bulk fill } \\
\text { resin composite material }\end{array}$ & $\begin{array}{l}\text { Voco } \\
\text { Germany, Cuxhaven }\end{array}$ & 1745566 & $\begin{array}{l}86 \% \text { w/w inorganic fillers, } \\
2.5-5 \% \text { BIS GMA, } \leq 2.5 \% \text { BIS EMA, } \leq 2.5 \% \\
\text { organically modified silicic acid, } \leq 2.5 \% \\
\text { aliphatic dimethacrylate }\end{array}$ \\
\hline Futura bond DC & $\begin{array}{l}\text { Dual curing self etching } \\
\text { bond reinforced with } \\
\text { nanoparticles }\end{array}$ & $\begin{array}{lr}\text { Voco } & \text { GmbH, } \\
\text { Germany, } & \text { Cuxhaven }\end{array} \mid$ & 1742689 & $\begin{array}{l}\text { 50-100\% Acidic adhesive monomer, 5-10\% BIS } \\
\text { GMA, 5-10\% 2hydroxyethyl methacrylate }\end{array}$ \\
\hline Bis-Silane & Silane coupling agent & $\begin{array}{l}\text { Bisco, Inc. } \\
\text { Schaumburg USA }\end{array}$ & & $\begin{array}{l}\text { Part A: }>=85 \% \text { ethanol,5-10\% } 3 \text { trimethoxysilyl } \\
\text { propyl-2-methyl-2-propenoic acid } \\
\text { Part B: } 30-50 \% \text { ethanol, } 1-5 \% \text { (85\% phosphoric } \\
\text { acid) }\end{array}$ \\
\hline Etching gel & Phosphoric acid gel & Pentron clinic, USA & & $37 \%$ Phosphoric acid gel \\
\hline
\end{tabular}




\section{Statistical analysis}

Statistical analysis was then performed using a commercially available software program (SPSS 19; SPSS, Chicago, IL, USA). As data were not normally distributed, significance of the difference between different groups within the same surface pretreatment was evaluated using Kruskall Wallis test. Mann Whitney U test was used for pairwise comparisons and to study the effect of surface pretreatment. The interaction of restoration and type of pretreatment variables was evaluated using 3 ways ANOVA. The level of significance was set at $\mathrm{P}<$ 0.05 .

\section{RESULTS}

\section{Comparison between different groups}

\section{a) Composite block}

Without thermocycling, the highest mean value was recorded in CoJet ${ }^{\circledR}$ system group, whereas the lowest mean value was recorded in control. Kruskall Wallis test showed that the difference between groups was statistically significant $(\mathrm{p}=0.003)$. Mann Whitney $U$ test revealed no significant difference between etching gel and CoJet ${ }^{\circledR}$ system groups (Table 2, Fig. 1)
With thermocycling, the highest mean value was recorded in etching gel group, whereas the lowest mean value was recorded in control. Kruskall Wallis test showed that the difference between groups was statistically significant $(\mathrm{p}=0.003)$. Mann Whitney $\mathrm{U}$ test revealed no significant difference between etching gel and CoJet ${ }^{\circledR}$ system groups (Table 2, Fig. 1)

\section{b) Hybrid ceramic block}

Without thermocycling, the highest mean value was recorded in $\operatorname{CoJet} \AA$ system group, whereas the lowest mean value was recorded in control. Kruskall Wallis test showed that the difference between groups was statistically significant $(\mathrm{p}=0.001)$. Mann Whitney $U$ test revealed a significant difference between Control, etching gel and CoJet ${ }^{\circledR}$ system groups (Table 3, Fig. 1)

With thermocycling, the highest mean value was recorded in CoJet ${ }^{\circledR}$ system group, whereas the lowest mean value was recorded in control. Kruskall Wallis test showed that the difference between groups was statistically significant $(\mathrm{p}=0.012)$. Mann Whitney U test revealed that etching gel was not significantly different from control, nor from CoJet@ system groups (Table 3, Fig. 1)

TABLE (2) Comparison between different groups of Composite block (Kruskall Wallis test)

\begin{tabular}{|c|c|c|c|c|c|c|c|c|c|}
\hline \multirow{2}{*}{\multicolumn{2}{|c|}{ Surface treatment }} & \multirow[b]{2}{*}{ Mean } & \multirow[b]{2}{*}{$\begin{array}{l}\text { Std. } \\
\text { Dev }\end{array}$} & \multirow[b]{2}{*}{$\begin{array}{l}\text { Std. } \\
\text { Error }\end{array}$} & \multicolumn{2}{|c|}{$\begin{array}{l}95 \% \text { Confidence } \\
\text { Interval for Mean }\end{array}$} & \multirow[b]{2}{*}{ Min } & \multirow[b]{2}{*}{ Max } & \multirow[t]{2}{*}{$\mathrm{P}$ value } \\
\hline & & & & & $\begin{array}{l}\text { Lower } \\
\text { Bound }\end{array}$ & $\begin{array}{l}\text { Upper } \\
\text { Bound }\end{array}$ & & & \\
\hline \multirow[t]{3}{*}{ No thermocycling } & Control & $5.91^{\mathrm{b}}$ & 1.42 & .54 & 4.59 & 7.23 & 3.20 & 7.54 & \\
\hline & Etching gel & $19.81^{\mathrm{a}}$ & 9.82 & 3.71 & 10.73 & 28.90 & 6.40 & 30.80 & $0.003 *$ \\
\hline & CoJet $\AA$ system & $22.54^{\mathrm{a}}$ & 9.97 & 3.77 & 13.32 & 31.76 & 6.33 & 34.18 & \\
\hline \multirow[t]{3}{*}{ With thermocycling } & Control & $3.52^{\mathrm{b}}$ & .98 & .37 & 2.61 & 4.43 & 1.61 & 4.91 & \\
\hline & Etching gel & $21.81^{\mathrm{a}}$ & 7.97 & 3.01 & 14.43 & 29.18 & 9.67 & 36.28 & $0.003 *$ \\
\hline & CoJet $\AA$ system & $19.38^{\mathrm{a}}$ & 9.43 & 3.57 & 10.66 & 28.11 & 3.49 & 35.33 & \\
\hline
\end{tabular}

Significance level $P<0.05$, * significant

Mann Whitney $U$ test: Means sharing the same superscript letter are not significantly different 
TABLE (3) Comparison between different groups of hybrid ceramic block (Kruskall Wallis test)

\begin{tabular}{|c|c|c|c|c|c|c|c|c|c|}
\hline \multirow{2}{*}{\multicolumn{2}{|c|}{ Surface treatment }} & \multirow[b]{2}{*}{ Mean } & \multirow[b]{2}{*}{$\begin{array}{l}\text { Std. } \\
\text { Dev }\end{array}$} & \multirow[b]{2}{*}{$\begin{array}{l}\text { Std. } \\
\text { Error }\end{array}$} & \multicolumn{2}{|c|}{$\begin{array}{l}95 \% \text { Confidence } \\
\text { Interval for Mean }\end{array}$} & \multirow[b]{2}{*}{ Min } & \multirow[b]{2}{*}{$\operatorname{Max}$} & \multirow[t]{2}{*}{$\mathrm{P}$ value } \\
\hline & & & & & $\begin{array}{l}\text { Lower } \\
\text { Bound }\end{array}$ & $\begin{array}{l}\text { Upper } \\
\text { Bound }\end{array}$ & & & \\
\hline \multirow[t]{3}{*}{ No thermocycling } & Control & $5.82^{\mathrm{c}}$ & 2.79 & 1.14 & 2.90 & 8.75 & 2.20 & 9.36 & \\
\hline & Etching gel & $10.02^{\mathrm{b}}$ & 3.78 & 1.43 & 6.53 & 13.52 & 5.08 & 15.23 & $0.001 *$ \\
\hline & CoJet ${ }^{\circledR}$ system & $24.08^{\mathrm{a}}$ & 2.71 & 1.02 & 21.57 & 26.59 & 21.05 & 29.09 & \\
\hline \multirow[t]{3}{*}{ With thermocycling } & Control & $3.90^{\mathrm{b}}$ & 2.71 & 1.02 & 1.40 & 6.40 & .00 & 7.12 & \\
\hline & Etching gel & $6.57^{\mathrm{a}, \mathrm{b}}$ & 2.28 & .86 & 4.46 & 8.69 & 3.30 & 8.96 & $0.012^{*}$ \\
\hline & CoJet ${ }^{\circledR}$ system & $9.34^{\mathrm{a}}$ & 2.58 & .98 & 6.95 & 11.73 & 5.89 & 12.34 & \\
\hline
\end{tabular}

Significance level $P<0.05$, * significant

Mann Whitney $U$ test: Means sharing the same superscript letter are not significantly different

\section{II-Effect of surface pretreatment}

Composite block: In control, a higher mean value was recorded without thermocycling, with a statistically significant difference ( $\mathrm{p}=0.018$ ). In etching gel, a higher mean value was recorded with thermocycling, with no statistically significant difference $(\mathrm{p}=0.949)$. CoJet巴 system recorded a higher mean value without thermocycling, with no statistically significant difference $(\mathrm{p}=0.565)$, (Table 4, Fig.1)
Hybrid ceramic block: In control, a higher mean value was recorded without thermocycling, with no statistically significant difference $(\mathrm{p}=0.366)$. In etching gel, a higher mean value was recorded without thermocycling, with no statistically significant difference $(\mathrm{p}=0.165)$. CoJet ${ }^{\circledR}$ system recorded a higher mean value without thermocycling, with a statistically significant difference $(\mathrm{p}=0.001)$, (Table 4, Fig.1)

TABLE (4) Comparison between surface treatment procedures (Mann Whitney U test)

\begin{tabular}{|c|c|c|c|c|c|c|c|}
\hline \multirow[t]{2}{*}{ Gp } & & \multicolumn{2}{|c|}{ Control group } & \multicolumn{2}{|c|}{ etching gel } & \multicolumn{2}{|c|}{ CoJet ${ }^{\circledR}$ system } \\
\hline & & $\begin{array}{l}\text { No thermo- } \\
\text { cycling }\end{array}$ & $\begin{array}{l}\text { With thermo- } \\
\text { cycling }\end{array}$ & $\begin{array}{l}\text { No thermo- } \\
\text { cycling }\end{array}$ & $\begin{array}{l}\text { With thermo- } \\
\text { cycling }\end{array}$ & $\begin{array}{l}\text { No thermo- } \\
\text { cycling }\end{array}$ & $\begin{array}{l}\text { With thermo- } \\
\text { cycling }\end{array}$ \\
\hline \multirow[t]{3}{*}{ Composite } & Mean & 5.91 & 3.52 & 19.81 & 21.81 & 22.54 & 19.38 \\
\hline & SD & 1.74 & 1.20 & 9.82 & 7.97 & 9.97 & 9.43 \\
\hline & $\mathrm{P}$ & \multicolumn{2}{|c|}{$0.018 *$} & \multicolumn{2}{|c|}{$0.949 \mathrm{~ns}$} & \multicolumn{2}{|c|}{$0.565 \mathrm{~ns}$} \\
\hline \multirow[t]{3}{*}{ Hybrid ceramic } & Mean & 5.82 & 3.90 & 10.02 & 6.57 & 24.08 & 9.34 \\
\hline & SD & 2.79 & 2.71 & 3.78 & 2.28 & 2.71 & 2.58 \\
\hline & $\mathrm{P}$ & \multicolumn{2}{|c|}{$0.366 \mathrm{~ns}$} & \multicolumn{2}{|c|}{$0.165 \mathrm{~ns}$} & \multicolumn{2}{|c|}{$0.001 *$} \\
\hline
\end{tabular}

Significance level $P<0.05$, * significant, ns=non-significant 


\section{III- Comparison between composite block and hybrid ceramic block}

In control, insignificantly higher mean value was recorded in composite block without thermocycling ( $\mathrm{p}=0.917)$, while with thermocycling insignificantly higher mean value was recorded in hybrid ceramic $(\mathrm{p}=0.735)$, (Table 5, Fig.1)

In etching gel, significantly higher mean value was recorded in composite block without thermocycling and with thermocycling $(\mathrm{p}=0.049$, 0.018 respectively), (Table 5, Fig.3)

In Cojet system, insignificantly higher mean value was recorded in hybrid ceramic without thermocycling $(\mathrm{p}=0.735)$, while with thermocycling significantly higher mean value was recorded in composite block ceramic ( $\mathrm{p}=0.028)$, (Table 5, Fig.1)

\section{IV- Interaction of variables (block group, resto- ration and type of pretreatment)}

Three ways ANOVA test revealed that each of the material type (composite/hybrid ceramic), the subgroup type group (control/etching/Cojet) and the thermocycling (Yes/No) variables resulted in a statistically significant difference $(\mathrm{p}=0.00, \mathrm{p}=0.00$, $\mathrm{p}=0.003$ respectively).

Interaction of the subgroup (control/etching/Cojet) variable with the thermocycling (Yes/No) variable and the material (composite/hybrid ceramic) variable showed a statistically significant difference $(\mathrm{P}=0.023, \mathrm{p}=0.001$ respectively). Moreover, interaction of thermocycling and material variable resulted in a significant difference $(\mathrm{p}=0.034)$. However, interaction of the 3 study variables (material, subgroup, thermocycling) was not statistically significant $(\mathrm{p}=0.165)$, (Table 6)

TABLE (5) Comparison between composite block and hybrid ceramic block (Mann Whitney U test)

\begin{tabular}{|c|c|c|c|c|c|c|c|}
\hline \multirow{2}{*}{ Gp } & & \multicolumn{2}{|c|}{ Control group } & \multicolumn{2}{c|}{ Etching gel } & \multicolumn{2}{c|}{ CoJet ${ }^{\circledR}$ system } \\
\cline { 3 - 8 } & & $\begin{array}{c}\text { No thermo- } \\
\text { cycling }\end{array}$ & $\begin{array}{c}\text { With thermo- } \\
\text { cycling }\end{array}$ & $\begin{array}{c}\text { No thermo- } \\
\text { cycling }\end{array}$ & $\begin{array}{c}\text { With thermo- } \\
\text { cycling }\end{array}$ & $\begin{array}{c}\text { No thermo- } \\
\text { cycling }\end{array}$ & $\begin{array}{c}\text { With thermo- } \\
\text { cycling }\end{array}$ \\
\hline \multirow{2}{*}{$\begin{array}{c}\text { Composite } \\
\text { block }\end{array}$} & Mean & 5.91 & 3.52 & 19.81 & 21.81 & 22.54 & 19.38 \\
\cline { 2 - 9 } & SD & 1.74 & 1.20 & 9.82 & 7.97 & 9.97 & 9.43 \\
\hline \multirow{2}{*}{\begin{tabular}{c} 
Hybrid ceramic \\
\cline { 2 - 8 }
\end{tabular}} & Mean & 5.82 & 3.90 & 10.02 & 6.57 & 24.08 & 9.34 \\
\hline \multicolumn{2}{|c|}{ P (Mann Whitney U) } & 2.79 & 2.71 & 3.78 & 2.28 & 2.71 & 2.58 \\
\hline
\end{tabular}

Significance level $P<0.05$, * significant, NS=non-significant

TABLE (6) Three ways ANOVA test

\begin{tabular}{|c|c|c|c|c|}
\hline Source & Type III Sum of Squares & Mean Square & $\mathrm{F}$ & Sig. \\
\hline Subgroups (control/etching/Cojet) & 2831.900 & 1415.950 & 42.027 & $.000 *$ \\
\hline Thermocycling & 322.203 & 322.203 & 9.563 & $.003 *$ \\
\hline Material (Composite/Hybrid ceramic) & 635.350 & 635.350 & 18.858 & $.000 *$ \\
\hline subgroup $*$ thermocycling & 268.855 & 134.428 & 3.990 & $.023 *$ \\
\hline Subgroup * material & 569.085 & 284.543 & 8.445 & .001 \\
\hline Thermocycling $*$ Material & 157.688 & 157.688 & 4.680 & $.034 *$ \\
\hline All_groups * Big_groups * VAR00001 & 124.473 & 62.237 & 1.847 & $.165 \mathrm{NS}$ \\
\hline
\end{tabular}

Significance level $P<0.05$, * significant, NS=non-significant 


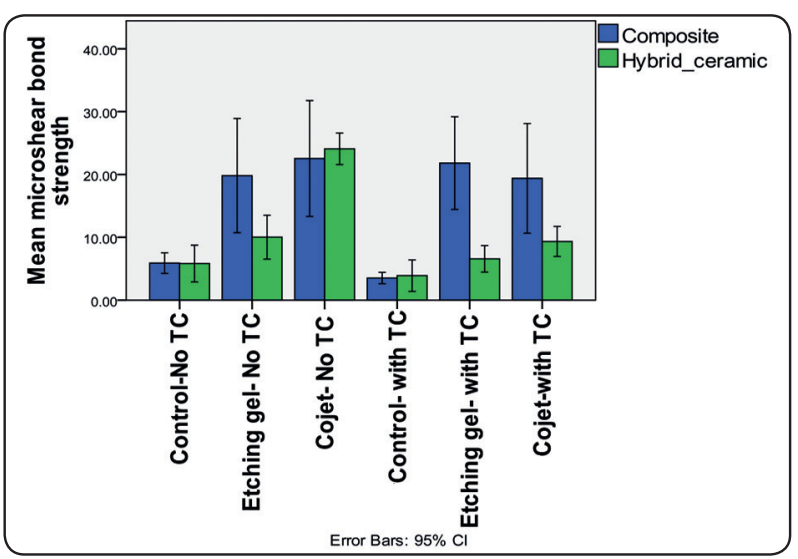

Fig. (1) Column chart showing mean values in different subgroups of composite block and hybrid ceramic block

\section{Failure mode analysis:}

The failure mode of the tested specimens analyzed using Scanning Electron Microscope SEM Model Quanta 250 FEG (Field Emission Gun) (FEI company, Netherlands), at magnification $80 \mathrm{X}$ was commonly mixed type of failure (adhesive failure between resin composite restoration and $\mathrm{CAD} /$ CAM blocks with cohesive failure within resin composite restoration) as presented figure 2 .

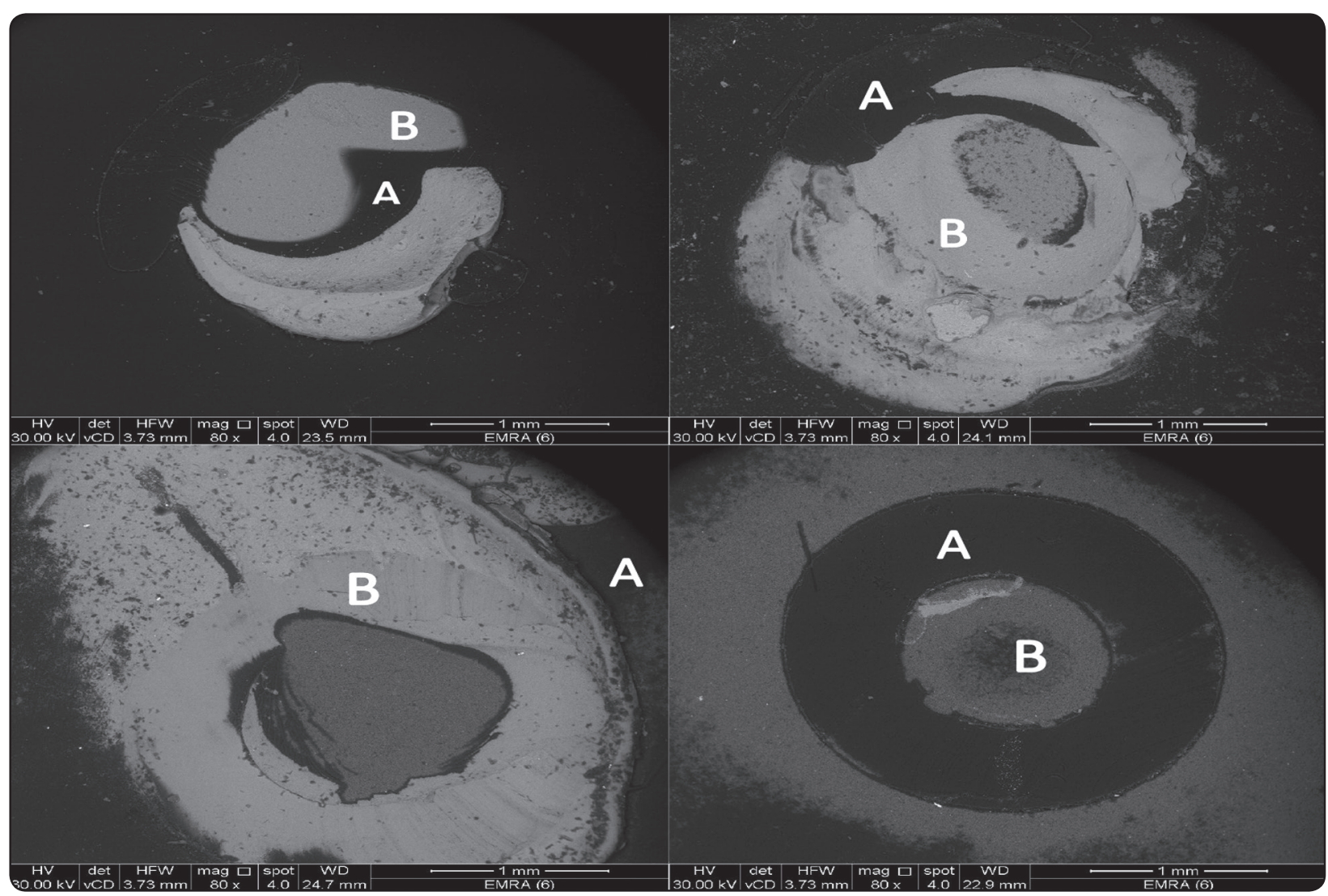

Fig. (2) Failure mode analysis A: adhesive failure, B: cohesive failure within resin composite restoration 


\section{DISCUSSION}

In the recent years the researches were directed to the development of dental materials appropriate for CAD/CAM applications, among the materials available to the dentist (chairside) are hybrid ceramic blocks and resin-composite blocks. The advantages of resin composite blocks is that they are pre-polymerized into ready-to-mill blocks.. Resin composite blocks are expected to be more fracture resistant than glass ceramics, especially when the thickness of the restoration is limited, and the fatigue resistant have been reported to be better. However, studies evaluating mechanical properties have reported indecisive results when comparing $\mathrm{CAD} / \mathrm{CAM}$ ceramic materials to resin composite blocks. $^{(1-3,7,17)}$

Fracture of dental ceramics or resin composite blocks is still the major problem in restorative dentistry. As these indirect esthetic restorations are placed into a tough oral environment where they are exposed to comparatively great mechanical loads (cyclical loading), as well as major fluctuations in both temperature (temperature cycling), $\mathrm{pH}$-values from the very acidic to the very basic, and even changes in salivary flow and buffering capacity over time. Hence, they are more subjected to fracture. The real challenge was to find the optimum way for a long lasting repair for these materials. ${ }^{(6,8,9,11,12)}$ Therefore, the aim of this study was to evaluate microshear bond strength of CAD/CAM composite block and hybrid ceramic block repaired by direct resin composite restoration with and without surface treatment. In the present study it was a priority to perform the microshear bond strength assessment for each specimen, once without thermocycling and another time after thermocycling. These factors obviously place great demands on the physical and chemical properties of the materials to somehow fulfil the clinical expectations of both performance and longevity. So all the specimens were thermocycled for aging the adhesive joint between the resin composite repair materials and hybrid ceramic or composite blocks to evaluate the performance of the bonded interfaces under standardized hydrothermal stresses.

The composite materials comprise two phases, the inorganic ceramic/glass phase and polymer matrix, which can be either cross-linked of linear polymer based. It is well-known that bonding of resin systems to the crosslinked polymer is challenging whereas liner polymers are easy to bond. ${ }^{(18)}$ Regarding restoration-surface pretreatment to adhesively bond the repair material to indirect composite blocks and hybrid ceramic blocks, several techniques were selected to prepare the CAD/CAM blocks surface prior application of repair materials to find the optimum way for a clinically sucessfull longstanding bonding between the CAD/CAM block materials and the direct resin composite materials used for repair. In previous studies various restoration-surface pre-treatments are commonly recommended, such as sandblasting with aluminiumoxide (27-50 $\mu \mathrm{m})$, silane coupling, solely application of a bonding agent, tribochemical silica sandblasting (Cojet, 3M ESPE), acid etching using hydrofluoric acid or phosphoric acid, etc. ${ }^{(16,17)}$

In this study, we aimed to evaluate the effect of restoration-surface pre-treatment of $\mathrm{CAD} /$ CAM composite blocks and hybrid ceramic blocks using different techniques: no surface treatment as control, 37\% phosphoric acid etching gel and the CoJet ${ }^{\circledR}$ system using $30 \mu \mathrm{m}$ silica coated alumina powder. All these surface treatments essentially create surface roughness and increase surface area to provide surface micro-retention.

The results of the present study it was clearly obvious that the thermocycling may affect the microshear bond strength. For Composite block: the control group recocorded a higher mean value was recorded without thermocycling, with a statistically significant difference $(\mathrm{p}=0.018)$. In etching gel, a higher mean value was recorded 
with thermocycling, with no statistically significant difference $(p=0.949)$. CoJet ${ }^{\circledR}$ system recorded a higher mean value without thermocycling, with no statistically significant difference $(p=0.565)$, (Table 4, Fig.1)

Regarding bonding to Hybrid ceramic block: In control, a higher mean value was recorded without thermocycling, with no statistically significant difference $(p=0.366)$. In etching gel, a higher mean value was recorded without thermocycling, with no statistically significant difference $(\mathrm{p}=0.165)$. CoJet ${ }^{\circledR}$ system recorded a higher mean value without thermocycling, with a statistically significant difference $(p=0.001)$, (Table 4, Fig.1)

Also the results revealed that in control group, insignificantly higher mean value was recorded in composite block without thermocycling $(\mathrm{p}=0.917)$, while with thermocycling insignificantly higher mean value was recorded in hybrid ceramic $(\mathrm{p}=0.735)$. In etching gel group, significantly higher mean value was recorded in composite block without thermocycling and with thermocycling ( $\mathrm{p}=0.049,0.018$ respectively). In Cojet system, insignificantly higher mean value was recorded in hybrid ceramic without thermocycling $(\mathrm{p}=0.735)$, while with thermocycling significantly higher mean value was recorded in composite block ceramic $(\mathrm{p}=0.028)$.

These results denotes that Sandblasting by Cojet system indeed increases surface roughness and surface area more than other surface pre-treatments, including etching with phosphoric acid. In this way, one may expect that the sandblasting done in this study might have contributed most to the microshear bond strength, while especially any additional benefit from silanization remains unclear ${ }^{(16,17)}$

The CAD/CAM ceramic materials used in this study have hybrid structure comprising both ceramic and composite. Besides, the phosphoric acid reacts with the glassy matrix that contains silica and selectively removes the glassy or crystalline phases of the restorative material. ${ }^{(18)}$ Therefore, phosphoric acid etching was considered as the most reliable treatment in this study. After a treatment with concentrated mineral acids and bases, the density of hydroxyl groups increases and a rough surface is created as some micropits are formed. ${ }^{(20)}$ Consequently, the surface of the ceramic microirregularities essential for micromechanical retention. However, the use of silane-coupling agents following phosphoric acid treatment or Cojet system might explain the non significant differences between surface treatments in case of composite blocks, opposite to ceramic blocks that revealed that the extra presence of silica obtained from the silica coated particles in the Cojet system, in the present study. The finding is in line with a previous study which demonstrated that phosphoric acid treatment, although the glass fillers were dissolved from the surface, increase bonding of resin to particulate filler composite resin. ${ }^{(18)}$ In the case of enhanced adhesion with silane coupling agent, it needs to keep in mind that silane promoted adhesion is liable to for hydrolysis and the interphae is therefore corrupted spontaneously during immersion in water. ${ }^{(18)}$

The adhesion strength of silane varies with different materials. The strongest adhesion is attained with silica, glass and quartz which form strong siloxane ( $\mathrm{Si} \mathrm{O} \mathrm{Si}$ ) linkages through the condensation with surface hydroxyl groups on the substrate. There are the two critical steps of resin substrate bonding formation with silane coupling agents: (1) silane and substrate bond formationactivated by acid, and (2) resin and silane bond formation - activated by light curing. Studies have certainly reported that incorporation of silanized filler particles in the resin matrix improves the physical and mechanical properties of resin composites in terms of mechanical strength and hydrolytic stability. ${ }^{(20)}$

In the present study, bond strength values significantly decreased following thermocycling. 
In accordance with the present study, a previous study by Campos et al. investigated the effect of thermocycling on bond strength of CAD/CAM ceramic to resin cement and concluded that the aging protocol significantly decreased the bond strength. Also previous studies have reported that bond strengths drastically decrease following aging and long-term water storage. The decrease in bond strength following thermocycling might be related to the small molecular size and high molar concentration of the water, which could negatively affect the thermal stability of the polymer. This might cause plasticization and eventually, hydrolytic degradation of the resin cement. Therefore, the durability of the bond between ceramic and resin based material needs to be ensured by surface treatments, which are based on increasing the surface roughness. ${ }^{(18)}$

According to the micro-shear bond test and analysis of the failure mode performed in the present study, it was revealed that each group with respect to resin composite repair system, surface treatment, and ceramic material mostly showed adhesive failure between resin cement and ceramic. This might indicate that the micro-shear test is an suitable method to evaluate the bond strength of ceramics to resin composite repair system. A strong bond between ceramics and resin composite repair system is certainly desirable. Therefore, the improved bond strength of both Vita Enamic and Grandio blocks in the present study could be attributed to their high filler content ( $86 \%$ by mass). ${ }^{(18)}$

Two types of ceramic structures were tested in the present study: resin matrix structure with filler (Grandio) and a ceramic network structure with resin matrix (Vita Enamic). The significant differences between bond strength results could be attributed to the microstructural differences of these CAD/ CAM blocks. However the chemical similarity in composition between the repair composite and the composite blocks was in favor to their sustained improved bond strength between them opposite to that in case of hybrid ceramic blocks.

SEM observation confirmed the bond strength results that were not different between the phosphoric acid-treated and Cojet system treated surfaces in all tested specimems.

\section{CONCLUSIONS}

\section{Under the limitation of the current study the following conclusions could be drawn:}

1. Grandio composite blocks is very promising materials and their optimum long lasting repair potentiality that offers to the clinicians great chance to easily repair the defective restoration with safety.

2. Surface treatment using Phosphoric acid or Cojet system greatly improve the bond strength between composite repair system and hybrid ceramic or composite blocks.

3. The bond performance of repaired composite blocks was much more greater than than that of repaired hybrid ceramic.

4. Thermocycling affect the bond durability of repaired hybrid ceramic blocks and composite blocks.

5. Further investigations focusing on the effect of different surface treatments to yield results that lead to concrete clinical recommendations are needed to evaluate the long term durability of new CAD/CAM materials.

\section{REFERENCES}

1. Beuer F, Schweiger J, Edelhoff D. Digital dentistry: an overview of recent developments for CAD/CAM generated restorations. Br Dent J 2008;204(9):505-11.

2. Miyazaki T, Hotta Y, Kunii J, Kuriyama S, Tamaki Y. A review of dental $\mathrm{CAD} / \mathrm{CAM}$ : current status and future perspectives from 20 years of experience. Dent Mater J 2009;28(1):44-56. 
3. Ruse ND, Sadoun MJ. Resin-composite blocks for dental CAD/CAM applications. J Dent Res 2014;93(12):1232-4.

4. Nguyen JF, Ruse D, Phan AC, Sadoun MJ. Hightemperature-pressure polymerized resin-infiltrated ceramic networks. J Dent Res 2014;93(1):62-7.

5. Phan AC, Tang ML, Nguyen JF, Ruse ND, Sadoun M. High-temperature high-pressure polymerized urethane dimethacrylate-mechanical properties and monomer release. Dent Mater 2014;30(3):350-6.

6. Chen C, Trindade FZ, de Jager N, Kleverlaan CJ, Feilzer AJ. The fracture resistance of a CAD/CAM resin nano ceramic (RNC) and a CAD ceramic at different thicknesses. Dent Mater 2014;30(9):954-62.

7. Hussain B, Thieu MKL, Johnsen GF, Reseland JE, Haugen HJ: Can CAD/CAM resin blocks be considered as substitute for conventional resins? Dent Mater. 2017 Dec;33(12):1362-1370.

8. Magne P, Schlichting LH, Maia HP, Baratieri LN. In vitro fatigue resistance of $\mathrm{CAD} / \mathrm{CAM}$ composite resin and ceramic posterior occlusal veneers. J Prosthodont Dent 2010;104(3):149-57.

9. Schlichting LH, Maia HP, Baratieri LN, Magne P. Noveldesign ultra-thin CAD/CAM composite resin and ceramic occlusal veneers for the treatment of severe dental erosion. J Prosthodont Dent 2011;105(4):217-26.

10. Pearson GJ, Bonsor SJ. Preventive and periodontal materials, implants and biomaterials. In: Pearson GJ, Bonsor SJ, editors. A clinical guide to applied dental materials. 1st edition Amsterdam: Churchill Livingstone; 2013.

11. Surdacka A, Strzyka AK, Rydzewska A. Changeability of oral cavity environment. Eur J Dent 2007;1(1):14-7.
[17] Sakaguchi RL, Powers JM. Craig's restorative dental materials. St. Louis, Missouri, USA: Mosby; 2002.

12. Özcan M. Fracture reasons in ceramic-fused-to-metal restorations. J Oral Rehabil 2003;30:265-9.

13. Reston EG, Filho SC, Arossi G, Cogo RB, Rocha CS, Closs LQ. Repairing ceramic restorations: final solution or alternative procedure. Oper Dent 2008;33:461-6.

14. Blatz MB, Sadan A, Kern M. Resin ceramic bonding: a review of the literature. J Prosthet Dent 2003;89:268-74.

15. Kocaa фgaoфglu H, Manav TY, Albayrak H. In vitro comparison of the bond strength between ceramic repair systems and ceramic materials and evaluation of the wettability. J Prosthodont 2017;26:238-43.

16. Matinlinna JP, Lung CYK, Tsoi JKH:Silane adhesion mechanism in dental applications and surface treatments: A review.Dent Mater. 2018 Jan;34(1):13-28.

17. Lührs AK, Pongprueksa P, De Munck J, Geurtsen W, Van Meerbeek B.Curing mode affects bond strength of adhesively luted composite CAD/CAM restorations to dentin.Dent Mater. 2014 Mar;30(3):281-91.

18. Cekic-Nagas I, Ergun G, Egilmez F, Vallittu PK, Lassila LV.Micro-shear bond strength of different resin cements to ceramic/glass-polymer CAD-CAM block materials. J Prosthodont Res. 2016 Oct;60(4):265-273.

19. Yoshihara K, Nagaoka N, Maruo Y, Nishigawa G, Irie M, Yoshida Y, Van Meerbeek B6.Sandblasting may damage the surface of composite CAD-CAM blocks.Dent Mater. 2017 Mar;33(3):e124-e135.

20. Matinlinna JP, Lung CYK, Tsoi JKH.Silane adhesion mechanism in dental applications and surface treatments: A review.Dent Mater. 2018 Jan;34(1):13-28. 